\title{
PosibilidADES SOCIALES DE PREVENCIÓN DE LA INFECCIÓN POR VIRUS DEL PAPILOMA HUMANO Y DE CÁNCER CERVICOUTERINO EN San Cristóbal de Las Casas, Chiapas, México
}

\author{
Social Possibilities of Prevention of Infection Human Papillomavirus and Cervical Cancer in \\ San Cristóbal de Las Casas, Chiapas, México \\ Mónica Adriana Luna-Blanco \\ Georgina Sánchez-Ramírez
}

Resumen: Este artículo muestra los resultados de un estudio cualitativo llevado a cabo de febrero a abril de 2012 y engloba la experiencia en tres talleres con población de escasos recursos, en total 68 participantes, hombres y mujeres, desde el enfoque de género y salud en San Cristóbal de Las Casas, Chiapas, con el fin de obtener información respecto al conocimiento que tenían en torno al virus del papiloma humano y su vínculo con el cáncer cervicouterino. Como resultado, se constató que la información biomédica en torno al cáncer cervical versus las prácticas de prevención reales de la población de estudio discrepan sustancialmente, ya que consideran más importante platicar sobre las prácticas sexuales en pareja, que utilizar protección o realizarse el Papanicolaou. Las campañas de detección oportuna no toman en cuenta estas realidades en su prevención.

Palabras clave: prevención, cáncer del cuello uterino, virus del papiloma humano, enfermedades de transmisión sexual, características culturales.

Abstract: This article shows the results of a qualitative study that was conducted between February to April in 2012. It comprises our work experience in three workshops with 68 poor people, mostly women, from the gender and health perspective, undertook in San Cristobal de Las Casas, Chiapas; in order to obtain information regarding their knowledge about the Human Papilloma Virus and its link to cervical cancer. As a result, we were able to contrast that the biomedical information about cervical cancer prevention practices and the actual prevention practices by the population differ substantially; since they consider more important to talk about sexual practices with their partner than protected sex or to have a pap test. Early detection campaigns are not considering these realities in its prevention programs.

Keywords: prevention, cervical cancer, human papillomavirus, sexually transmitted diseases, cultural background.

\footnotetext{
Mónica Adriana Luna Blanco, maestra en antropología social y doctora en ecología y desarrollo sustentable por El Colegio de la Frontera Sur. Temas de especialización: antropología médica y género. Correo electrónico: mluna@ecosur.mx.

Georgina Sánchez Ramírez, doctora en sexualidad. Profesorainvestigadora en El Colegio de la Frontera Sur-Unidad San Cristóbal de Las Casas. Temas de especialización: género y salud de las mujeres en la edad mediana, indicadores sociodemográficos desde el enfoque de género y educación para la sexualidad. Correo electrónico: gsanchez@ ecosur.mx.
}

Enviado a dictamen: 17 de junio de 2013.

Aprobación: 16 de agosto de 2013.

Revisiones: 2. 


\section{Introducción}

E cáncer cervicouterino es la segunda causa de mortalidad entre la población femenina en México (Luna, Fajardo y Sánchez, 2013; Globocan, 2008; OPS, 2007). Esta patología es catalogada como un problema de salud pública y se han destinado recursos económicos, materiales y científicos para implementar en el país un Programa de Detección Oportuna que evite y disminuya la mortalidad entre la población femenina. No obstante esta inversión en recursos humanos y tecnológicos, la morbilidad y mortalidad por esta causa prevalece.

Se ha identificado que los virus del papiloma humano de alto riesgo están presentes en el 99\% de lesiones cervicouterinas y de cáncer in situ (SSA, 2008: 11-12). En el año 2009 ocurrieron en México 4107 muertes por cáncer cervicouterino (SSA, 2010). El estado de Chiapas, junto con Zacatecas, Veracruz, Colima y Campeche, presenta las tasas de mortalidad más altas por esta causa, particularmente en los grupos de mujeres de 25 a 64 años (Freyermuth, 2011; Domínguez et al., 2011).

Para proporcionar una idea general de la problemática en la entidad, nos respaldamos en los datos del Sistema Nacional de Información en Salud citados por Freyermuth (2011), donde se identifica que, en Chiapas, de 2007 a 2010 la Secretaría de Salud documentó 50 casos de jóvenes menores de 24 años con cáncer cervicouterino y registró casos de muerte por este motivo en un período de cinco años tras el inicio de la vida sexual activa.

En 2009, en México se registraron 12 muertes por este tipo de cáncer en mujeres menores de 25 años (ver bases de datos de mortalidad del Sistema Nacional de Información en Salud citados en Freyermuth, 2011). De igual forma, en el estudio de Freyermuth se documentaron casos de jóvenes de 18 años que fueron sometidas a procedimientos de conización, lo que implica que ya se les había diagnosticado displasia severa pese a su corta edad.

Asimismo, en el año 2010 la tasa nacional de mortalidad por cáncer cervicouterio observada en 100 000 mujeres de 25 años y más fue de 13.5, mientras que en el estado de Chiapas fue de 19.0, de modo que la diferencia es de 5.5 (SSA, 201lb).

Por lo que respecta a la infección por virus de papiloma humano (VPH), las frecuencias reportadas en México oscilan entre el 14.4\% y el 51.7\%. El VPH ha sido detectado en prácticamente todos los casos de cáncer invasor (Domínguez et al., 2011).

Este panorama nos lleva a cuestionarnos: ise puede hablar de elementos clave en la prevención de la infección por VPH y en la detección oportuna del cáncer cervical? ¿Los avances biomédicos incluidos en los esfuerzos de los programas de detección continúan siendo insuficientes?

Si se ha establecido desde la medicina una identificación etiológica en la infección por VPH y su vínculo con el cáncer cervicouterino, ieste avance biomédico se refleja hoy en una mejor comprensión de la enfermedad por parte de la población femenina y, en consecuencia, en un mejor estado de salud sexual entre la población de la ciudad de San Cristóbal de Las Casas? ¿Qué sucede con los conocimientos de la población en torno a las prácticas de prevención en salud sexual?

\section{Del cuidado y la prevención}

El enfoque de la prevención es un elemento clave en la identificación, tanto de la infección por VPH, como de lesiones cervicouterinas y cáncer. Tanto el concepto como la práctica de la prevención difieren entre la población atendida y el sector médico, que trabaja según los lineamientos de la biomedicina. Analizar estas diferencias conceptuales y prácticas en torno a la prevención resulta un elemento clave, ya que permite una adecuada identificación de acciones efectivas para disminuir la infección por VPH, así como el desarrollo de lesiones cervicouterinas y cáncer.

La prevención primaria se enfoca en evitar la aparición de la enfermedad utilizando medidas que disminuyan los factores de riesgo y favoreciendo comportamientos y hábitos más saludables entre la población (Sebastián, 2001: 184-185). En el caso de la infección por VPH, algunas prácticas modificables pueden ser el uso de preservativos o el mantenimiento 
de una relación monógama, lo cual disminuiría considerablemente la exposición a la infección.

La prevención secundaria tiene como objetivo reducir la mortalidad y la morbilidad mediante un diagnóstico precoz que incluya aspectos relacionados con el tratamiento (Sebastián, 2001). En este recurso se ubican los programas de detección oportuna, las campañas publicitarias que brindan información a la población y la respuesta eficaz de las instituciones ante diagnósticos de lesiones cervicouterinas, en todo lo cual es determinante la comunicación entre el personal médico y las mujeres que requieren atención.

En México, la Secretaría de Salud, a través de la Norma Oficial Mexicana NOM-014-SSA2-1994, ${ }^{1}$ para la prevención, detección, diagnóstico, tratamiento, control y vigilancia epidemiológica de cáncer cervicouterino en la atención primaria, indica que deben considerarse como factores de riesgo en el cáncer del cuello del útero las siguientes características en la población femenina:

[...] ser mayor de 25 años; inicio temprano de relaciones sexuales (antes de los 19 años); promiscuidad [sic] de la pareja; multiparidad (más de cuatro partos); embarazo temprano (antes de los 18 años); infección cervical por virus del papiloma humano; antecedentes de enfermedades de transmisión sexual; tabaquismo; factores nutricionales como la deficiencia de folatos y vitaminas A, C y E, y nunca haberse practicado un estudio citológico. El CaCu es más común después de los 35 años, lo que sugiere infección a temprana edad y progresión lenta a cáncer (SSA, 2010; ver también Sánchez, Luna y Vargas, 2013).

Recientemente, la prevención primaria de la infección por VPH se realiza mediante la aplicación de la vacuna contra dos tipos de alto riesgo más frecuentes, asociados a lesiones cervicales precursoras del cáncer cervicouterino, y dos tipos de VPH de bajo riesgo asociados a presencia de condilomas y verrugas genitales, las cuales no ponen en riesgo la vida de las personas que lo portan. ${ }^{2}$ Por ser más de 100 los tipos de cepas de VPH, este tipo de vacuna implica que la protección es limitada y que las mujeres jóvenes que se vacunan ahora tendrán que, una vez iniciada su vida sexual, realizarse periódicamente un examen citológico, al igual que las mujeres que no han sido vacunadas. Esta vacunación - de prevención primaria-se implementa a nivel nacional desde el sector salud y se ofrece de igual manera en el sector privado con el objetivo de disminuir en un futuro los índices de mortalidad y morbilidad por este padecimiento.

El programa de vacunación está dirigido a niñas de nueve años en adelante que no hayan iniciado vida sexual. Lamentablemente, no se incluye a los varones en la vacunación, quienes son portadores, mayormente asintomáticos, del virus. A ellos no se les aplica la vacuna por cuestiones de costo-beneficio, con el argumento de que los índices de cáncer de pene y ano en los hombres son mínimos en comparación con los de cáncer cervicouterino en las mujeres, por lo que se desestima el potencial de prevención que tendría el diseñar y aplicar una vacuna similar para varones, en tanto que son ellos los principales agentes de transmisión como un derivado de las prácticas sexuales que socialmente son alentadas en ellos.

Cabe cuestionarse la viabilidad de este programa de vacunación ya que, además de considerar que sólo está destinado a dos tipos de VPH de alto riesgo - lo cual deja una amplia gama de otros tipos de alto riesgo sin protección-, la información que recibe la población es confusa; por ejemplo, se les informa que la vacuna es para evitar el cáncer cervicouterino, cuando en realidad está dirigida a dos tipos de VPH asociados a esta enfermedad. Se genera además la percepción de que las niñas y adolescentes vacunadas no necesitarán después realizarse la prueba del Papanicolaou.

Asimismo, este esquema de vacunación no aporta elementos que refuercen el cuidado de la salud sexual y la corresponsabilidad entre mujeres y varones. En el panorama de la prevención primaria por la infección del virus del papiloma humano no se consideran las prácticas sexuales, en las que el contagio por VPH es sólo uno más entre los múltiples riesgos de enfermedades e infecciones por contacto sexual, además de embarazos no planeados.

La Secretaria de Salud, a través del Programa de Detección Oportuna del Cáncer Cervicouterino, hace 
hincapié en que la mortalidad por cáncer cervical se puede evitar si éste es detectado oportunamente, lo cual implica el tamizaje citológico de las mujeres que han iniciado su vida sexual. En los documentos de operación del Programa se señala que un impedimento es que las mujeres, objetivo del tamizaje, no acuden a realizarse la prueba del Papanicolaou, y muchas acuden demasiado tarde (SSA, 2008).

Fajardo Ortiz (2012) cuestiona acertadamente la detección oportuna desde el planteamiento médico: ise trata de una prevención primaria de la infección o de prevenir el desarrollo y dar tratamiento oportuno?

En México, el énfasis se coloca en lo segundo. El Programa se enfoca en la prevención del desarrollo y en el tratamiento oportuno a las mujeres con diagnóstico positivo de lesiones cervicales y cáncer por infección de VPH, sin mencionar una adecuada educación para el disfrute de una sexualidad saludable y plena:

\section{Por otra parte el estudio de la enfermedad conduce a estrategias preventivas más que curativas. Un proceso de traducción del conocimiento entre las áreas básica y clínica resultaría previsible en el sentido de que la investigación sobre las causas biológicas de la enfermedad, como lo es la infección por VPH, llevaría por consecuencia a buscar estrategias de intervención en salud pública para cortar la red causal (Fajardo, 2012: 15)}

Lo que tenemos entonces es información biomédica sobre la infección de VPH, el desarrollo etiológico de la enfermedad - sus estadios y tratamientos de acuerdo con cada caso - y la Norma Oficial Mexicana para la Detección, Tratamiento y Control Oportuna del Cáncer Cervicouterino, así como normas internacionales que buscan disminuir la brecha de mortalidad por este padecimiento en los países más pobres.

Si bien esto es importante dada la prevalencia del padecimiento, no es suficiente en cuanto a las posibilidades de generar estrategias y acciones de prevención primaria entre la población. Se apuesta a que las mujeres - ejes del funcionamiento de este programa de detección oportuna- acudan a realizarse la prueba del Papanicolaou periódicamente y se minimiza lo que esto implica para ellas y para el sistema de salud. Diversos estudios al respecto lo constatan (Aranda, 2010; Castro y Salazar, 2001; Luna, Fajardo y Sánchez, 2013).

Lo que para el sector médico es una acción preventiva, para la población no lo es, y no lo es porque en general ese conocimiento aún no ha sido transmitido de forma accesible y contextualizada, de tal manera que se incluya a los varones en los procesos de prevención. Tampoco se han tomado en cuenta las condiciones en que se ofrece la realización de la prueba de Papanicolaou a muchas mujeres - falta de privacidad, de higiene, de profesionalismo o de calidez-, lo cual desalienta aún más la práctica sobre la que se apuesta casi el cien por ciento de la prevención.

Esta situación no es específica del cáncer cervicouterino dado que en otras patologías, como el cáncer de mama, es posible observar dinámicas similares, como las campañas de detección oportuna, en las que se debe considerar que el lenguaje y los factores psicosociales son fundamentales y

[...] puede ser la clave para transmitir un mensaje adecuado y provocar un elevado grado de acogida y concientización. No es lo mismo plantear una campaña desde el miedo, la amenaza de muerte, etc. Que desde la importancia del papel activo que debemos jugar en nuestra salud y, por lo tanto, apelar a nuestra responsabilidad (Sebastián, 2001: 188).

Considerando esa realidad social, en este trabajo se buscó contrastar la información biomédica sobre el cáncer cervical con las prácticas de prevención reales de la población de estudio.

\section{Camino metodológico}

Planteamos el estudio desde una perspectiva de género para buscar problematizar las necesidades e implicaciones de cuidado en salud sexual de las mujeres y los varones. Debido a la naturaleza de la información que se pretendía recabar, se optó por metodologías 
cualitativas, ya que permiten profundizar, desde la perspectiva de las personas y sus contextos, los fenómenos relacionados con la salud y la enfermedad.

Se optó por la modalidad de taller considerando que nos facilitaría acceder a información sobre valores, normas y actitudes para alcanzar el logro de los objetivos de investigación, los cuales fueron expuestos de forma clara a quienes participaron, junto con la relevancia de su participación para lograr dichos objetivos.

El taller es un espacio de trabajo donde se genera conocimiento colectivo, se intercambian ideas y se facilita a la población la reflexión sobre la problemática analizada, de tal forma que el conocimiento se genera recíprocamente. En su desarrollo, apoyándonos en una metodología participativa y considerando como punto de partida la experiencia de las personas participantes, se buscó el diálogo, la participación, la cooperación y el encuentro de propuestas encaminadas a afrontar los problemas identificados. Si bien el el número de talleres y su duración fueron limitados por la disposición de tiempo de quienes participaron y por el presupuesto, los resultados muestran una instantánea de la realidad en un momento y contexto específico que se puede extrapolar a otras realidades como se aprecia en la discusión de este estudio. ${ }^{3}$

Se realizó una carta descriptiva y se contó para el desarrollo de los talleres con la colaboración de una médica citóloga y de una pedagoga, así como de algunas estudiantes de servicio social que colaboran con la Dirección de Equidad y Género del municipio de San Cristóbal de Las Casas, quienes apoyaron en el llenado de las cédulas de información, en especial con la población sin escolaridad. ${ }^{4}$ En especial con la población sin escolaridad. Se solicitaron datos generales como edad, ocupación y escolaridad, así como datos relevantes para la investigación, como inicio de vida sexual, número de parejas sexuales y si les había sido detectada una infección por VPH o lesiones cervicouterinas.

En nuestro caso, los talleres no implicaban una intervención directa sobre las personas y su cuerpo - como ocurre cuando se realizan investigaciones a partir de resultados de pruebas de laboratorio-. Se trataba de indagar sobre sus representaciones sociales y estados emocionales en torno a las infecciones de transmisión sexual.

Se buscaba influir sobre los asistentes a los talleres como personas con agencia, de tal manera que pudieran, con la información otorgada, acudir a una detección oportuna. ${ }^{5}$ Asimismo, se orientó sobre los tres niveles de atención - primario, de detección en las clínicas de salud; secundario, clínicas de colposcopía; y de tercer nivel, hospital de oncología- - Este enfoque de trabajo de taller participativo se suma a la perspectiva planteada por Montoya, para quien

[...] el cuerpo de conocimientos sobre la salud sexual ha crecido en forma asimétrica y en una menor proporción que otros referentes de las ciencias de la salud. Reconocer que es necesario, justo y conveniente indagar por la sexualidad de las personas y las poblaciones ha significado una ruptura paradigmática que, se espera, lleve a la reflexión en el personal de salud sobre sus carencias de conocimiento y capacitación. No obstante, también alude a la profunda necesidad de dar a conocer a la población el derecho a la salud sexual (Montoya, 2007: 169).

Así, con la realización de los talleres con población abierta buscamos movilizar los recursos personales de los asistentes y proporcionar herramientas que los guíen hacia una práctica de cuidado de la salud sexual, haciendo énfasis en específico en la importancia de la realización continua de la prueba del Papanicolaou. ${ }^{6}$

Las ideas centrales propuestas para abordar, indagar y compartir con la población desde el enfoque de género en los talleres fueron

a. información sobre la infección por virus de papiloma humano;

b. información sobre cómo se hace el diagnóstico de infección por virus de papiloma humano (en qué consiste un estudio citológico o Papanicolaou qué es una colposcopia y qué hacer ante un Papanicolaou anormal);

c. prácticas de cuidado y prevención. 
La invitación a participar en los talleres se realizó mediante carteles informativos dirigidos a mujeres de veinte años en adelante y se convocó a través de espacios públicos y medios de información como la radio y la página de facebook de la Dirección de Equidad, Género y Desarrollo del municipio de San Cristóbal de Las Casas.

Se realizaron tres talleres en esta ciudad en colaboración con la Dirección de Equidad y Género del municipio; uno de ellos en la zona centro de la ciudad —en la biblioteca municipal —; el segundo en la Casa de Salud de Zacualpa, comunidad cercana situada a diez minutos de la ciudad; y el tercero en el salón comunitario de la colonia San Juan de Los Lagos, al sur de la ciudad. La población que acudió es mestiza.

Aunque la invitación se dirigió a mujeres, en dos talleres hubo una escasa presencia de hombres que acudieron para acompañar a sus esposas y por curiosidad, y que aportaron datos relevantes para el conocimiento del tema.

Uno de los supuestos básicos sobre los que se realiza esta investigación es que, siendo el cáncer cervicouterino una enfermedad considerada como problema de salud pública - a la cual está expuesta toda la población femenina una vez iniciada su vida sexuallas estrategias para su detección y tratamiento oportuno generalizan a la población femenina minimizando la relevancia de considerar diferencias de estrato social, escolar y cultural, entre otros factores. Ello trae como resultado que el Programa de Detección Oportuna no sea efectivo para todas las mujeres.

De ahí que metodológicamente optamos por elegir población abierta y, de esta manera, contar con un panorama general de los conocimientos legos sobre la infección y el cáncer cervicouterino. La información fue recabada en los materiales aplicados en cada taller - carteles, hojas de trabajo, esquemas corporalesy en un diario de campo. Además, fue grabada y se realizó un registro fotográfico. Para la sistematización, organización e interpretación de la información, al término de cada taller se realizó una lectura detenida de la información para identificar categorías y su saturación teórica, así como la interrelación entre los temas abordados.

\section{La población de estudio}

Se trabajó en la ciudad de San Cristóbal de Las Casas, la cual, según el Censo de población y vivienda del INEGI, en el año 2010 contaba con 185917 habitantes, de los cuales 88996 son hombres y 96921 mujeres (INEGI, 2010). El porcentaje de mujeres de 15 a 29 años alcanzaba el 31\%, y el de mujeres de 60 años y más era de $5.7 \%{ }^{7}$

En términos demográficos, el número de defunciones de mujeres durante 2011 fue de 341 - no se especifica causa de muerte- - . El grado promedio de escolaridad de la población de 15 años y más en 2010 era de 8.3 años de estudio. Por lo que respecta a servicios de salud, la población derechohabiente en 2010 era de 99 367, mientras que la población sin derechohabiencia era de 81822. Se reportó que el promedio de médicos por unidad médica era de 2.7 (INEGI, 2010).

A los talleres acudieron en total 68 personas: 7 varones y 61 mujeres. El rango de edad en las mujeres abarcó de los 16 hasta los 68 años, y de los 19 a los 61 años en el grupo de los hombres. El promedio de edad en el grupo de hombres fue de 38 años, y de 41 años en el grupo de las mujeres. La escolaridad era baja en todo el grupo: el 34\% cursó algún grado de primaria, un 18\% terminó la primaria y el 18\% concluyó la secundaria. Todos los varones cursaron algún grado escolar, más no las mujeres, quienes en su mayoría no contaban con escolaridad, mientras que otras no dieron respuesta alguna a esta pregunta.

El inicio de la vida sexual para ambos grupos, en promedio, fue similar: 18 años y medio. En los varones, los rangos de edad abarcaban de los 17 a los 20 años. No así en las mujeres, quienes reportaronn haber iniciado actividad sexual desde los 13 años hasta los 27.

Si bien se identificó que hubo mujeres que iniciaron su actividad sexual a los 13 años (30\%), la mayoría de ellas lo hicieron después (el 70\%), tres años más tarde, -entre los 16 y los 20 años-. Por lo que respecta al número de parejas sexuales, un varón respondió haber tenido sólo una pareja sexual, mientras que los demás respondieron haber tenido entre dos y tres parejas. Entre las mujeres, sólo cinco respondieron haber tenido dos parejas sexuales - el 8\% de la población participante-, 
mientras que la mayoría de ellas —el 86\%— sólo ha tenido una pareja sexual. Tres participantes expresaron no haber iniciado aún vida sexual

\section{Resultados}

\section{De la transmisión de VPH al cáncer}

Desde la línea de la biomedicina, la cual plantea que para el desarrollo del cáncer cervical es necesario no sólo la infección del VPH, sino también la persistencia de éste en el cuerpo femenino (Sánchez, Uribe y Conde, 2002; Tirado et al., 2005; SSA, 2008; Tobar, 1999), y siendo el VPH un virus de transmisión sexual, interesa entonces evidenciar cuáles son las creencias y conocimientos de la población respecto a las infecciones de transmisión sexual.

Hombres y mujeres expresaron lo que para ellos es una infección de transmisión sexual, mencionaron cuáles son las más comunes — sobre las que más han escuchado o recibido algún tipo de información-y la forma de transmisión. Las respuestas del grupo de varones resultan más concretas —en lo que se refiere a proporcionar una "definición"- y utilizan incluso lenguaje biomédico, como por ejemplo "conjunto de afecciones infectocontagiosas".

En los grupos de mujeres, las respuestas fueron más complejas ya que refirieron nombres de enfermedades de transmisión sexual pero no explicaron en qué consistían. También mencionaron un grupo de infecciones genitales y vaginales que pueden tener otras causas además del contacto sexual. Reconocieron que se adquieren por contacto sexual sin protección —es decir, sin usar preservativos-, hicieron hincapié en que una causa eran los varones que tienen más parejas — simultáneas o sucesivas-, y señalaron la falta de limpieza vinculada a la presencia de infecciones de transmisión sexual.

En cuanto a las formas de transmisión, para los varones estaba de por medio el contacto sexual sin protección -ellos sí especificaron tipos de prácticas sexuales por contacto oral, vaginal o anal-y la transfusión sanguínea. En estas respuestas habría que preguntarse si esta creencia provenía de la información sanitaria en torno al VIH-Sida, o qué tan expuesta está la población a recibir este tipo de transfusiones.

Para las mujeres, la transmisión va más allá de tener relaciones sexuales sin protección; nuevamente el peso recayó en el número de parejas sexuales que tienen los varones, en la falta de comunicación con la pareja y en la falta de higiene. Aparece un discurso más: "por no cuidarse". Entonces, ¿qué implicaciones tiene esta frase? ¿Quién o quiénes deben cuidarse? De acuerdo con las respuestas, las prácticas de cuidado girarían en torno a la higiene personal, a no tener diversas parejas sexuales sin el uso del preservativo y a evitar el contacto con sangre infectada.

Tanto hombres como mujeres señalaron en primer lugar al VIH-Sida como una infección de transmisión sexual, seguido por la gonorrea y la sífilis. El virus del papiloma humano fue también señalado y sólo los varones mencionaron la "cresta de gallo", que es como popularmente se conoce la manifestación clínica del VPH de bajo riesgo; se trata de condilomas observables en el área ano-genital y los varones lo nombran porque en el pene es más visible.

Una de las características de la infección por VPH y de las lesiones cervicouterinas es que sólo en sus etapas más avanzadas se manifiestan síntomas físicos, lo cual aumenta la vulnerabilidad al cáncer, ya que la población, al no sentirse enferma, no considera relevante hacerse un Papanicolaou.

Paradójicamente, los participantes sí identificaron un listado de molestias o síntomas vinculados a la presencia de infecciones de transmisión sexual, algunos relacionados con estados avanzados de cáncer cervicouterino, como el sangrado abundante o el dolor al tener relaciones sexuales. Otros síntomas -físicos y anímicos - que mencionaron de ITS fueron ardor, "ardor en el cuello de la matriz" (sic), comezón, flujo, dolor, inflamación, dolor al orinar, pérdida de ánimo, decaimiento, verrugas o calentura, entre otros. Los varones señalaron erupciones genitales, fiebre alta, ardor y secreciones, manchas y disminución de peso.

Una vez que observamos que la población nombró el VPH como infección de transmisión sexual, el siguiente 
paso consistió en identificar qué sabían sobre ella y si era posible identificar cuándo una persona tenía esta infección en su cuerpo.

Surgieron cinco grupos de respuestas. En primer lugar, las respuestas fueron de desconocimiento: "no sé". Algunas personas expresaron haberlo "escuchado mucho", pero no entender qué es. Aquellas que afirmaron saber más sobre el vPH lo señalaron como "un virus muy peligroso y contagioso". Otro grupo reconoció que el VPH "lo tiene el hombre desde chiquito, él lo contagia a la mujer, pero él no lo desarrolla y nosotros sí." Los grupos restantes de respuestas giraron en torno al efecto que tenía sobre las mujeres; por un lado, señalaron que, si en la mujer se detecta a tiempo, hay que dar tratamiento, y finalmente se reconoció la infección por VPH como "una enfermedad muy dolorosa, que se cura con tratamiento".

Hasta este punto aún no se había relacionado de manera directa el VPH con el cáncer cervicouterino. Sólo se esbozó cuando indagamos si era posible identificar si una persona era o no portadora del virus. Las respuestas diferenciadas nuevamente fueron negativas en un inicio, de tal manera que unos no sabían si era posible, mientras que otros afirmaron que no era posible detectar el virus. Después, se señaló que en el hombre era más difícil, pero que en la mujer sí era posible detectarlo.

Otro grupo respondió que es posible identificar las lesiones que el virus ocasiona y que la colposcopia es el procedimiento médico a través del cual se pueden observar estas lesiones. Sólo cinco mujeres respondieron haber recibido resultados positivos en su Papanicolaou; esto es, les fue detectada una infección por VPH, lesiones cervicales o cáncer cervical.

\section{Posibilidades de prevención: de lo biomédico a lo sociocultural}

Indagamos con la población de estudio qué acciones realizaban - o deberían realizar - para protegerse de contraer una infección de transmisión sexual, si consideran que estas acciones son de utilidad para evitar la transmisión y, finalmente, cómo evitar que una infección por VPH avance a cáncer cervical.
Los discursos giraron en dos sentidos: unos de carácter negativo, cuando "no hacemos nada" por falta de dinero, por desconocimiento, porque incomoda al hombre o porque no sabemos cómo cuidarnos; y otros de carácter proactivo, hacer uso del preservativo - masculino, ya que el femenino es desconocido por la mayoría-, tener relaciones sexuales sólo con la pareja, aprender a cuidarse y buscar una buena comunicación con la pareja. Hacerse el Papanicolaou es otra acción señalada.

En cuanto a si estas prácticas son de utilidad en el cuidado de la salud sexual, las respuestas giraron hacia un sentido ideal, ya que reconocieron que no, "al contrario, corremos más riesgo porque no sabemos", y porque "no se sabe bien cómo cuidarse." Estos discursos nos llevaron a replantear si las acciones enlistadas previamente constituían el ideal de cuidado, pero estaban alejadas de las posibilidades cotidianas de atención de la salud sexual.

Para evitar que una infección por VPH avance a cáncer cervical, los discursos de la población giraron en dos sentidos. Uno ligado al enfoque biomédico, esto es, realizarse el Papanicolaou frecuentemente, asistir al doctor "para que nos chequen y nos detecten a tiempo", hacerse estudios y asistir a pláticas informativas. El otro sentido gira en torno a la pareja, en específico "tener o mejorar la comunicación con la pareja" y hacer uso del preservativo masculino.

Ahora bien, los datos obtenidos en los talleres nos muestran que no es posible abordar únicamente el aspecto biomédico de la infección del VPH en las mujeres, sino que existe una complejidad que rodea a la representación de la infección de VPH y del cáncer cervical para la población de estudio que impacta directamente en los elementos de vulnerabilidad y de prevención.

Identificamos diversas esferas presentes en la vida cotidiana de las mujeres que obstaculizan un estado de salud sexual favorable. En primera instancia, se encuentra el nivel individual - la mujer, su cuerpo-. Loa participantes expresaron no "conocer y explorar" sus cuerpos, no tocarlos. Señalan la falta de "autocuidado", un concepto que se promueve mucho desde la medicina preventiva, donde se responsabiliza a 
la población de su estado de salud, independientemente de otros factores.

Sólo las mujeres señalaron prácticas de higiene, cuestiones reproductivas que las hacen más vulnerables, "nos desgastamos mucho, por el hombre y por los hijos", la desidia -otro concepto que surge desde la biomedicina - y negligencia de su parte por no acudir al médico, la vergüenza de acudir, la falta de confianza en la pareja, el miedo y "no darle importancia a nuestra vida”, son los elementos predominantes en esta esfera.

En la segunda esfera tenemos las relaciones de pareja. A este respecto manifiestan las negativas de sus parejas varones para "aceptar protegerse" y que éstos no se "cuidan" cuando tienen relaciones sexuales con otras mujeres, lo cual evidencia prácticas de infidelidad, mala comunicación y algunas conductas "machistas", como prohibir a sus parejas que acudan a revisión ginecológica porque "creen que la intimidad es de su propiedad". El siguiente testimonio lo ejemplifica: "Los esposos luego nos dicen: no te vas a ir a hacer el Pap (sic) porque ningún hombre te va a ver la cucharita, sólo yo lo lavo, lo meneo, lo uso" (mujer de San Juan de los Lagos).

En la tercera esfera se encuentra el nivel social, donde identificamos dos factores, el educativo y el religioso. En cuanto al religioso, los testimonios refieren que en algunos casos, los curas (sic) o guías espirituales les dicen que no deben dejar que las revisen porque es pecado, así como es pecado que las niñas se toquen y exploren su cuerpo. Estas creencias implican una carga de señalamiento negativo por la sociedad, difícil para muchas mujeres que son diagnosticadas con cáncer cervical, ya que se cuestiona su comportamiento sexual.

Respecto a lo educativo, las mujeres refirieron que les hacía falta tener más información ya que las escuelas carecen de educación sexual. La baja escolaridad dificulta asimilar algunos conceptos biomédicos o incluso poder leer sus resultados de la prueba de Papanicolaou. Una ausencia es que no mencionan la información de trípticos, carteles o anuncios del sector salud encaminados a la detección oportuna del cáncer cervical.

La última esfera corresponde al sector salud. Aquí interviene la accesibilidad a los centros de detección y tratamiento. Ejemplo de esto es que las mujeres de Zacualpa expresaron que ellas sólo recibían atención cuando iban las brigadas, pero cuando bajaban a la ciudad ahí no les hacían caso. La accesibilidad no sólo tiene que ver con contar con una clínica de medicina familiar o un hospital de tercer nivel de atención cerca de su lugar de residencia; implica las relaciones que surgen entre las mujeres usuarias y el personal médico, lo cual en no pocas circunstancias resulta en una mala calidad en la atención, en la toma de la prueba o en la explicación de los resultados, entre otras cuestiones vinculadas con su salud. Interviene asimismo el aspecto económico ya que las mujeres dejan de acudir a los centros de salud o a consultorios privados porque no pueden pagar la consulta o, en caso de ser necesario, los estudios posteriores que confirmen el diagnóstico.

\section{Discusión}

En este apartado discutiremos cuál es la situación entre la población estudiada en torno a lo que Fajardo Ortiz (2012) plantea como la traducción del conocimiento. Esta traducción implica que la investigación básica desarrolle un conocimiento aplicable que impacte en la práctica médica y en su correspondiente transmisión de conocimientos a la población. Para nuestro estudio, esta búsqueda de la traducción del conocimiento implicaría que la población tenga incorporado, al menos, el vínculo de la infección de VPH con el cáncer cervicouterino, así como la relevancia de realizarse el Papanicolaou como práctica de prevención secundaria.

Lo primero que identificamos es que los factores de riesgo, tanto para contraer una infección por VPH como el cáncer cervical, se vierten en una serie de enlistados que pueden ser eficaces para dar la información al personal de salud y a la población atendida, así como para reportar datos epidemiológicos. Sin embargo, esto sólo logra dar una visión fragmentada que no permite comprender los elementos en su conjunto ni profundizar en los procesos sociales de enfermar (Aranda, 2010; Martínez, 2008). Por ejemplo, iqué pasa con una mujer que no fuma, que inició su vida sexual después de los 20 años, nulípara, que sólo ha tenido 
una pareja sexual? ¿Considerará ella relevante para su salud, con base en los factores de riesgo enlistados en los programas de prevención del cáncer cervical, realizarse la prueba de Papanicolaou periódicamente?

En el abordaje de los procesos de salud/enfermedad/ atención, se corre un gran riesgo si asumimos esta dependencia teórica del modelo biomédico y se busca únicamente sobre este modelo construir estrategias de prevención como, por ejemplo, el desarrollo de nuevas tecnologías para la prevención del cáncer cervicouterino, como pruebas y técnicas moleculares para la identificación de ADN de VPH más específicas, como la captura de híbridos. Ibáñez y Durá advierten al respecto que los avances tecnológicos han separado al médico del paciente, convirtiéndolos a ambos en dos sistemas independientes. En muchas ocasiones, la tecnología avanzada se interpone en la relación entre el personal médico y los enfermos, de tal forma que la relación que entre ambas partes debería existir queda despersonalizada (Ibáñez y Durá, 1989 en Manso et al., 2001: 219). Esto además prioriza la tecnología médica costosa y presente sólo en las grandes zonas urbanas y para quienes tienen acceso, sobre todo económico-y deja de lado la prevención en salud, la actuación antes de que ocurra el daño — de mucho menor costo financiero y social一.

Otro elemento que debemos tener presente en el análisis es el proceso por el cual la biomedicina construye sus objetos, desarrolla sus biotecnologías y crea nuevas identidades y representaciones culturales (Martínez, 2008). La biomedicina no es un ente abstracto producto del avance tecnológico, sino que refleja relaciones de poder, relaciones de género y valores que la sociedad establece, $y$, con base en estos fundamentos socioculturales, se conjuga con los conocimientos legos de la población, que comparte a su vez esas relaciones de poder y de género y reproduce esos valores. Un ejemplo de ello es la postura que asumen muchas mujeres de mostrarse pasivas ante las exploraciones ginecológicas y ante la explicación poco clara de sus resultados del Papanicolaou, por lo que en muchos casos no solicitan que sus parejas sean también diagnosticadas.
Mishler (1981 en Martínez, 2008) advirtió sobre las presunciones culturales e ideológicas en las que descansa la "cientificidad" de la biomedicina. Entre ellas destaca la definición de enfermedad como una desviación de la norma biológica bajo una doctrina de que existe una etiología específica de las enfermedades, esto es, la unicausalidad o una multicausalidad establecida en factores de riesgo - esto es claro en el caso del VPH de alto riesgo, el cual se considera un factor predominante para el cáncer cervical-

Una limitación metodológica a la hora de utilizar la técnica de talleres es que, en general, no hay tiempo suficiente para profundizar sobre algunos aspectos entre toda la información que surge. En este sentido, identificamos cuatro elementos que los hombres y mujeres participantes en los talleres señalan como fundamentales para las prácticas de prevención. El primer elemento es el cuidado. Las palabras utilizadas son "tenemos que cuidarnos", "el autocuidado", "los hombres no se cuidan". Sin embargo, no especificaron qué actitudes y acciones implican esas prácticas de cuidado.

El segundo elemento es el uso del preservativo. Éste fue señalado como una herramienta de protección para evitar el contagio de infecciones de transmisión sexual, incluyendo el VPH. En este sentido quedan inquietudes en cuanto a cuál es la frecuencia real del uso del preservativo masculino entre las parejas, en qué situaciones y con qué parejas lo usan y con cuáles no; por ejemplo, si son esposos, concubinos, parejas ocasionales o novios.

El tercer punto señalado es la realización del estudio del Papanicolaou. Esto implica no sólo acceder a la prueba de tamizaje, sino además comprender cuáles son las relaciones sociales que surgen ahí, cómo las mujeres son agentes pasivos o activos en ese proceso y, en caso de ser identificada una lesión cervical, cómo enfrentan ellas los siguientes estudios de confirmación y tratamiento. Habría que indagar, además, la frecuencia en la realización del Papanicolaou para poder afirmar que, efectivamente, esta práctica es realizada y con ello disminuye el riesgo de desarrollar un cáncer.

Por último, pero no menos importante, está la comunicación con la pareja, elemento que resaltó en 
cada uno de los temas que se trabajaron en el taller. En este punto cabe recalcar que tanto hombres como mujeres asumen que los hombres tienen más experiencias sexuales con más de una mujer y que, en consecuencia, si ellos no se "protegen", sus parejas reconocidas socialmente - por matrimonio o por unión libre - resultan perjudicadas. ¿Cuáles serían los temas que se espera tratar en esa comunicación en pareja? ¿Cómo el hecho de abordarlos favorecería el cuidado de la salud sexual en ambos?

Estos cuatro elementos deben ser retomados para entender las dinámicas de prevención primaria y secundaria a fin de vincularlas efectivamente con la propuesta de atención biomédica, reconociendo que están presentes factores de género que exacerban la vulnerabilidad de contraer enfermedades de transmisión sexual. En general, estos factores son: la tolerancia con la que la sociedad acepta la "promiscuidad" masculina, entendida esta última como las prácticas sexuales que los varones sostienen con muchas parejas sexuales, ya sea de forma simultánea, ocasional o secuencial, incluyendo el sexo servicio — además de sin protección-, la asignación social de un valor mayor a lo masculino y el beneplácito social ante la pasividad y abnegación femenina (Herrera y Campero, 2002).

\section{Consideraciones finales}

¿Los avances biomédicos se reflejan en una mejor comprensión delapoblación de este estudio de lainfección del VPH y el cáncer cervicouterino? ¿Esta comprensión se refleja en acciones de prevención oportuna?

La población sí tiene un conocimiento sobre las infecciones de transmisión sexual y sobre el cáncer cervicouterino, aunque este conocimiento no coincida del todo con el conocimiento biomédico, lo cual nos alerta sobre la calidad de la eficacia de los programas de detección oportuna; no obstante, concordamos con Fajardo Ortiz (2012) quien señala como principal hallazgo de su estudio, centrado en la atención a las mujeres con diagnóstico de cáncer cervicouterino, que no ocurre un proceso adecuado de traducción del conocimiento biomédico.
Para el caso que nos ocupó en relación con el conocimiento sobre la infección por VPH, se constató que, si bien la población identifica la infección por VPH como un asunto de trasmisión sexual, no se logra establecer que dicha infección es la precursora de las lesiones cervicouterinas y que ésta puede llegar incluso a ocasionar lesiones cervicales y cáncer.

Las prácticas preventivas primarias que menciona la población giran en torno a las relaciones de pareja mejorar comunicación y fidelidad-, así como asumir el discurso del autocuidado, esto es, hacerse la prueba del Papanicolaou aunque no se comprenda completamente su utilidad ni los procesos de la enfermedad.

Los avances en la medicina ginecológica y los servicios de salud pública destinados a la detección oportuna del cáncer cervical desde el enfoque biomédico, proponen un modelo de detección oportuna como el Papanicolaou. Por ese motivo continúa siendo imprescindible construir un puente de comunicación entre las creencias populares de la prevención primaria y el modelo biológico lesional que explica la enfermedad, ya que los términos médicos que definen las enfermedades no son muchas veces adecuados para lo que padecen las personas (Huicochea, 2009); es decir, que es frecuente que tanto los diagnósticos como los tratamientos médicos estén alejados de las creencias sobre los orígenes y tratamientos que los legos utilizan - por ejemplo, atribuir enfermedades al consumo de alimentos fríos o calientes, y que al mencionárselo al personal médico éstos se burlen de tales atribuciones, considerándolas producto de la ignorancia del paciente-

Hemos constatado, al menos en este estudio, lo importante que es entender la infección del VPH en todas sus dimensiones, en específico en la dinámica social y cultural de las prácticas sexuales. De igual forma, las prácticas preventivas deben incluir a los varones en la información y su papel en la trasmisión del virus (Reartes, 2005).

Se debe superar la visión de que la prevención secundaria a través de la citología del Papanicolaou es un logro médico, al cual los cuerpos femeninos sólo deben acudir, asumiendo que realizarse el Papanicolaou 
es una actitud de autocuidado que se espera y exige de las mujeres. Para que esto suceda e impacte como una práctica secundaria preventiva, el acceso a información adecuada y oportuna es un requisito indispensable para reducir el riesgo de enfermar, pero esta información debe estar contextualizada social y culturalmente a fin de que se cumplan las metas y objetivos de los planes y programas de atención y detección del cáncer cervical. De ahí la relevancia de esta investigación, la cual se centra en los saberes y conocimientos de las mujeres y los hombres respecto al padecimiento y su vínculo con el ejercicio de la sexualidad.

Queda abierta a futuras investigaciones laindagación sobre la representación social de la vacuna del VPH entre la población, en vías de identificar dos aspectos relevantes: en primera instancia, cómo se está dando el proceso de traducción del conocimiento biomédico en torno a la aplicación de la vacuna; y, en segundo lugar, más importante aún, si esta medida puede efectivamente tener impacto como mecanismo de prevención entre la población o si, por el contrario, se perfila como una acción emergente ante la carencia de una adecuada educación sexual, afectiva y erótica en las nuevas generaciones, lo que implicaría confrontar atávicas posturas políticas, religiosas y culturales, pero permitiría dotar de mayores elementos a las personas para que asumieran con más autonomía las decisiones sobre su cuerpo, su salud y su vida.

Implica, a su vez, la necesidad de repensar cómo se están invirtiendo recursos en la atención de padecimientos como el VPH y el cáncer cervicouterino; si realmente el costo/beneficio de la vacuna es positivo para la población o para un sector farmacéutico; si lo invertido en inmunizaciones es similar a lo que se dispone para tratamientos de quienes ya han dado positivo en cáncer cervicouterino, incluidas todas las mujeres que viven en sectores como los del presente estudio, en el margen del margen.

Aunque muchos cuestionamientos no se han podido responder por las limitaciones de este estudio, hemos pretendido sentar precedentes sobre interrogantes que deben seguir siendo investigadas en pro de la salud de las poblaciones actuales y futuras.

\section{Notas}

${ }^{1}$ Secretaria de Salud, "Norma Oficial Mexicana NOM-014SSA2-1994, Para la prevención, detección, diagnóstico, tratamiento, control y vigilancia epidemiológica del cáncer cervicouterino", en Diario Oficial 2007 [31 de mayo 2010]. 〈http://www.generoysaludreproductiva. gob.mx/IMG/pdf/NOM014SSA2_31_de_mayo_2007. pdf>.

${ }^{2}$ En México están disponibles dos vacunas, Cervarix y Gardasil. La vacuna Cervarix -del laboratorio GlaxoSmithKlain GSK-, sólo incluye los tipos 16 y 18, los más comunes causantes del cáncer cervicouterino. La vacuna Gardasil —de los laboratorios Merck Sharp $\&$ Dhome MSD - es tetravalente, incluye los tipos de VPH de bajo riesgo 6 y 11 y los tipos de alto riesgo 16 y 18 .

${ }^{3}$ Los talleres formaron parte del trabajo de campo de la investigación doctoral Conocimientos y prácticas por virus del papiloma humano y su vínculo con el cáncer cervical en las ciudades de San Cristóbal de Las Casas, Chiapas.

${ }^{4}$ En la cédula de información se explicó que la información que era solicitada a los participantes sería de carácter confidencial y, si ellos estaban de acuerdo, se utilizaría para los fines de la investigación resguardando siempre la identidad de los sujetos. Se aclaró que podían continuar en todo el taller o retirarse si así lo deseaban.

${ }^{5}$ La información que fluye bajo esta metodología es de carácter colectivo y no pone en riesgo su integridad física o moral.

${ }^{6}$ Se puso especial atención en señalar a las asistentes la formación de las encargadas de impartir el taller —una antropóloga y una médica citóloga-. Cuando surgían inquietudes sobre casos clínicos, se recomendaba acudir a una cita médica ginecológica en el lugar de su preferencia, si estaban afiliadas a servicios de atención públicos.

${ }^{7}$ No se encontraron datos de mujeres entre 30 y 60 años.

\section{Referencias bibliográficas}

Aranda Gallegos, Patricia y María del Carmen Castro Vázquez, (2008) "Para una epidemiología sociocultural en el estudio del cáncer cervicouterino: 
experiencias de investigación”, en Región y Sociedad, vol. XX, núm. especial 2. México, El Colegio de Sonora, pp. 93-126.

Aranda Gallegos, Patricia, (2010) Los motivos de la "desidia". Estudio sociocultural de los saberes legos sobre el Papanicolaou y el cáncer cervicouterino. México, El Colegio de Sonora.

Castro Vázquez, María del Carmen y Gilda Salazar Antunes, (2001) Elementos socioculturales en la detección del cáncer cervicouterino. Un estudio en Hermosillo, Sonora. México, El Colegio de Sonora.

Centros para el Control y la Prevención de Enfermedades, (2007) Virus del Papiloma Humano: información sobre el VPH para los médicos. Transmisión, prevención, detección, manejo clínico. s.l., Centros para el Control y la Prevención de Enfermedades.

Domínguez Arrevillaga, Sergio et al., (2011) "Frecuencia genotípica del virus del papiloma humano en población general de la frontera sur de México" en Enfermedades Infecciosas y Microbiología. Vol. 31, núm. 1, enero-marzo, pp. 6-10.

Fajardo Ortiz, David Guillermo, (2012) Análisis de un proceso de traducción del conocimiento en salud: el caso del cáncer cervicouterino. Tesis de maestría. México, El Colegio de la Frontera Sur.

Freyermuth Enciso, Graciela (coord.), (2011) Monitoreo de la atención a las mujeres en servicios públicos del sector salud. México, Instituto Nacional de las Mujeres/CIESASSureste.

Globocan, (2008) Fast Stats. México. IARC Section of Cancer Information. Disponible en: http:// globocan.iarc.fr/factsheets/populations/factsheet. asp? ${ }^{2}=484$ \#OMEN [consultado el 14 de julio de 2013].

Herrera, Cristina y Lourdes Campero, (2002) "La vulnerabilidad e invisibilidad de las mujeres ante el VIH/SIDA: constantes y cambios en el tema" en Salud Pública de México. Vol. 44, núm. 6, pp. 554-564.

Huicochea Gómez, Laura, (2009) Cuerpo, percepción y enfermedad: un análisis sobre enfermedades musculo esqueléticas en Maltrata, Veracruz. México, Universidad Autónoma de México-Instituto de Investigaciones Antropológica/El Colegio de la Frontera Sur.
Instituto Nacional de Estadística y Geografía (INEGI), (s.f.) México en cifras. Información nacional por entidad federativa y municipios. México, INEGI. Disponible en: http://www3.inegi.org.mx/sistemas/mexicocifras/ default.aspx [consultado el 15 de mayo de 2013].

Lizano Soberón, Marcela, Adela Carrillo García y Adriana Contreras Paredes, (2009) "Infección por virus del papiloma humano: epidemiología, historia natural y carcinogénesis" en Cancerología. Núm. 4, pp. 205-216.

López Saavedra, Alejandro y Marcela Lizano Soberón, (2006) "Cáncer cervicouterino y el virus del papiloma humano: la historia que no termina" en Cancerología. Núm. 1, pp. 31-55.

Luna Blanco, Mónica, Horacia Fajardo Santana y Georgina Sánchez Ramírez, (2013) "Cáncer cervicouterino, ienfermedad femenina o feminización de la enfermedad?" en Aurelia Flores Hernández y Adelina Espejel Rodríguez (coords.), Género y desarrollo. Problemas de la población I. México, Universidad Autónoma de Tlaxcala/El Colegio de la Frontera Sur/Colegio de Posgraduados en Ciencias Agrícolas/Universidad Autónoma de Nuevo León, pp. 89-114.

Martínez Hernáez, Ángel, (2008) Antropología médica. Teorías sobre la cultura, el poder y la enfermedad. España, Anthropos Editorial.

Manso, M.I. et al., (2001) "Relación médico-paciente en oncología mamaria: aspectos psicosociales" en Cristina Bernis Carro, María Rosario López Giménez, Consuelo Prado Martínez y Sebastián Herranz, Julia (eds.) Salud y género. La salud de la mujer en el umbral del siglo XXI. XIII Jornadas de Investigación Interdisciplinarias. Madrid, Instituto Universitario de Estudios de la Mujer- Universidad Autónoma de Madrid, pp. 219-225

Montoya Montoya, Gabriel Jaime, (2007) "La ética del cuidado en el contexto de la salud sexual y reproductiva" en Acta Bioethica. Vol. XIII, núm. 2, pp. 168-175.

Ochoa Díaz, Héctor, Esmeralda García Parra y Rosario García Miranda, (2007) "Previniendo el cáncer cervicouterino en áreas indígenas marginadas de Chiapas" en Ecofronteras. Núm. 32, pp. 22-26. 
Organización Panamericana de la Salud (OPS), (2007), ¿"México", en Salud en las Américas. Volumen II. Países. México, OPS. Disponible en: http:// new.paho.org/mex/index.php?option=com content\&view=article\&id=203:la-salud-en-lasamericas-capitulo-mexico\&catid=780:la-salud-demxico-en-cifras\&Itemid=310 [consultado el 14 de julio de 2013].

Palacio Mejía, Lina Sofía, (2008) Significados y prácticas de las mujeres frente a la prevención, diagnóstico y tratamiento del cáncer cervicouterino a comienzos del siglo XXI: una visión desde la perspectiva de género. Tesis de doctorado. México, El Colegio de México.

Palacio Mejía, Lina Sofía, Eduardo Lazcano Ponce, Betania Allen Leigh y Mauricio Hernández Ávila, (2009) "Diferencias regionales en la mortalidad por cáncer de mama y cérvix en México entre 1979 y 2006" en Salud Pública de México. Vol. 5l, núm. 2, pp. 208-219.

Reartes Peñafiel, Diana Laura, (2005) La infección por el virus del papiloma humano (VPH) conflictividades, miedos y ambivalencia. Un estudio con parejas y médicos en un hospital de tercer nivel de atención en la ciudad de México. Tesis de doctorado. México, CIESAS.

Sánchez Ramírez, Georgina, Luna Mónica Blanco y Pilar Vargas, (2013) Infección por virus de papiloma humano y prevención de cáncer cervical. Aguascalientes, CENEJUS/ ECOSUR/ECICH.

Sánchez Alemán, Miguel Ángel, Felipe Uribe Salas y Carlos Conde González, (2002) "La infección por el virus del papiloma humano, un posible marcador biológico de comportamiento sexual entre estudiantes universitarios" en Salud Pública de México. Vol. 44, núm. 5, pp. 442-447.
Sebastián Herranz, Julia, (2001) "Factores psicosociales en el cáncer de mama” en Cristina Bernis Carro, María Rosario López Giménez, Consuelo Prado Martínez y Sebastián Herranz, Julia (eds.), Salud y género. La salud de la mujer en el umbral del siglo XXI. XIII jornadas de Investigación Interdisciplinarias. Madrid, Instituto Universitario de Estudios de la Mujer-Universidad Autónoma de Madrid, pp. 183-200.

Secretaría de Salud (SSA), (2008) Programa de acción específico 2007-2012. Cáncer cervicouterino. México, Subsecretaria de Prevención y Promoción de la Salud. Secretaría de Salud (SSA), (2010) Sistema Nacional de Información en Salud, base de datos. México, la Secretaría. Disponible en: http:/www.sinais.salud.gob.mx/mortalidad/index.html [consultado el 3 de febrero 2011].

Secretaría de Salud (SSA), (20lla) Cuentas en salud reproductiva y equidad de género. Estimación 2009 y comparativo 2003-2009. México, Instituto Nacional de Salud Pública.

Secretaria de Salud (SSA), (201lb) Rendición de cuentas en salud 2010. México, Instituto Nacional de Salud Pública.

Tirado Gómez, Laura Leticia et al., (2005),"Factores de riesgo de cáncer cervicouterino invasor en mujeres mexicanas" en Salud Pública de México. Vol. 47, núm. 5, pp. 342-250.

Tobar Alas, Saul David, (1999) Factores socioculturales y errores de operación que obstaculizan el programa de detección oportuna de cáncer cervicouterino en la población femenina con vida sexual activa del paraje de Chiquinivalvó, municipio de Zinacantán, México. Tesis de licenciatura. México, Universidad Autónoma de Chiapas.

Turner, Bryan S., (1987) Medical power and social knowledge. Londres, Sage Publications. 